\title{
Study to Determine Qualitative Characteristics in Customer Service Positions in Supermarkets (Super North Case)
}

\author{
Francisco Javier Espinoza Valencia \\ Universidad de Sonora \\ Juan Carlos Robles Ibarra \\ Universidad de Sonora \\ Victor Manuel Delgado Moreno \\ Universidad de Sonora
}

\begin{abstract}
The present investigation was carried out through a quantitative and cross-sectional approach with which the qualitative characteristics of the customer service positions in medium-sized supermarkets within the modern group are known, and the results obtained show that: In the dimension, assessment of the attitude of the employees to the client, tells us that the variable in the Department of Service and Customer Service are kind, throws that $r=.726^{* *}$, Sig. (bilateral) .000 .. The study shows that the employees of the customer service departments at all times must respond in a cordial and friendly manner and have knowledge of the teams with which they work to provide a quality service, and the concern shown by customers about a home service shows that customers at all times demand more of the staff for which they are served and which becomes an area of opportunity for supermarkets.
\end{abstract}

Keywords: Supermarkets, Qualitative Characteristics, Job Profile

\section{INTRODUCTION}

The present investigation was carried out in medium supermarkets within the modern group, which for more than two decades have appeared in different colonies of the city of Hermosillo, and several cities in the state of Sonora. These types of organizations are constantly growing, as well as competing more and more among them. And they in turn with large supermarkets, with convenience stores, as well as groceries or neighborhood stores. These supermarkets began in 1997 in this city, with the name of Super del Norte, currently has 74 stores of which 36 are in this city and 38 in different cities of the State of Sonora.

The research to these establishments was qualitative and quantitative in which the essential personal competences were identified, such as attitude and capacity, having a greater influence on customer satisfaction, and allows to identify the qualitative competences of the same. These competences are focused directly on kindness, as well as operational knowledge of the positions. For this reason, organizations in these times of constant change must seek tools that allow them to have a better 
management of their human resources and especially the selection of people looking for employees with features focused on customer service, guidance and satisfaction, to obtain competitive advantages in this type of organizations.

\section{Overall Objective}

Identify the qualitative characteristics of the profiles of customer service positions in medium-sized supermarkets, to achieve an efficient recruitment and selection of personnel.

\section{Specific Objectives}

- Identify the essential competences of customer service staff in supermarkets.

\section{Justification of the Investigations}

The research leads to know the qualitative skills of the job profiles, which has a direct and positive influence on customer satisfaction in supermarkets. The information provided by this research shows us that competences are related to attitude and ability in terms of kindness, service and availability to serve the client. All this leads to perform the functions of recruitment and selection more efficiently, in this type of commercial organizations, in order to eliminate the empiricism that exists in these.

\section{THEORETICAL FRAMEWORK}

\section{Retail or Retail}

"The retail merchant understands himself as a retail seller. The concept of Castillo Berthier (1994, p.64), clarifies the term: "retail or detail is the activity in which a merchant sells directly to the last consumer". Here the bidder is specified and its distribution in detail; that is, the final consumer in minimum units "(Bocanegra, 2008, pp. 63.64).

The same author, Bocanegra Gastélum, presents "the definition of the National Institute of Statistics, Geography and Informatics (INEGI) to complement these concepts," the retailer is understood as the merchant who sells retail. Retail trade, such as the purchase of goods in large quantities - wholesale for resale in small quantities to final consumers directly. "(Bocanegra, 2008, pp. 64).

Marshall, quoted by Bocanegra, 2008, mentions ... this integration of private retail trade, which offers personal consumption goods in detail, likewise, he analyzed it in two large groups: 1) The large commercial establishment, and 2) The small shopkeeper. The first group called the large commercial establishment, characterized it as follows: a) purchases in better conditions, b) has cheaper and safer transport and c) offers a greater variety of goods, appropriate to the tastes of consumers. The characteristics of the second group are: a) sales are on credit known for portfolio sales, according to the shopkeepers themselves, b) they require a small amount of investment, c) the business can subsist with a minimum investment (Bocanegra, 2008, p 64).

The first group called the large commercial establishment is called modern and is identified by the following: a small number of establishments. They are medium or large according to the number of people employed, the former occupies 26 to 50 workers and the latter from 50 onwards. They request specialized personnel for the different departments. Both are divided into: self-service and departmental stores.

The self-service stores are composed of: wineries, membership clubs, specialty stores and supermarkets, the latter in turn subdivided into hypermarkets and megamarkets, depending on the area dedicated to sales exclusively, the hypermarkets have a space between 4,500 and 10,000 square meters, the megamarkets of 10,001 square meters and up (Bocanegra, 2008, page 65).

This modern retail or retail group acquires the latest technology for the administration, organization, control and sale of merchandise. In other words, it constantly updates all the operations of the company. The infrastructure includes investment amounts that allow opening larger sales areas of the market. They have spaces specially designed for parking. They operate mainly for the middle and upper income population strata. The purchased quantities of merchandise are in large volumes and very diversified so 
they can offer between 40,000 and 90,000 different products. They resort continuously to advertising by brochures, television, radio press or via internet. The productivity per worker is high. They have vertical integration with the agricultural and industrial producer and even their own, that is, they elaborate or control the production of the goods they offer (Bocanegra, 2008).

The second group called the small shopkeeper is known as traditional, since it retains the same characteristics from its origins. Its particularities are: a large number of micro and small establishments, the buses employ up to 5 workers, the small ones from 6 to 20. Within the fixed micro-store are groceries in detail or also called neighborhood stores, miscellanies, and specialized stores such as greengrocers, bakeries, butchers and fishmongers and gifts and so on. In general, they are attended by their owners and there is no self-service in it. The products they distribute are not very diverse: in food they offer some edible groceries and some perishable products. Of the latter only offer 6 types of products, they also provide inedible groceries and junk foods. There is no diversity of goods and they do not handle the 24 remaining lines of articles, unlike the modern one, which participates in all the lines and of each one offers a great variety (ANTAD, 2000, pp. 6-7 in Bocanegra, 2008, p. 65).

The same author, Bocanegra Gastélum, comments that, "The most representative activity class of this group is groceries. The infrastructure consists of fixed installations in an exhibition and warehouse sales area of no more than 50 square meters. In the technological field they do not have cash registers for the collection of the goods or their control. They have 1 or 2 special cooling devices for products that require it. They do not have vertical or horizontal integration. They acquire the merchandise from their suppliers in small volumes, therefore the cost is higher, which is reflected in the price of the product, which they offer with a high marketing margin. The items obtained for resale, are made in the same way, that is, in very small proportions, however, they are of high turnover. The establishment does not have special parking, they are located mainly in the home of their owners, who are located mainly in low and middle income areas. The productivity obtained per worker is very low "(Bocanegra, 2008, pp. 65.66).

Carmen Bocanegra Gastélum in her book "The trade in Mexico and its environment with globalization, structure and shows the retail trade or retail in Mexico through figure 1, gives greater clarity to the classification, both traditional group and of the modern

\section{FIGURE 1 \\ STRUCTURE OF RETAIL TRADE IN MEXICO}

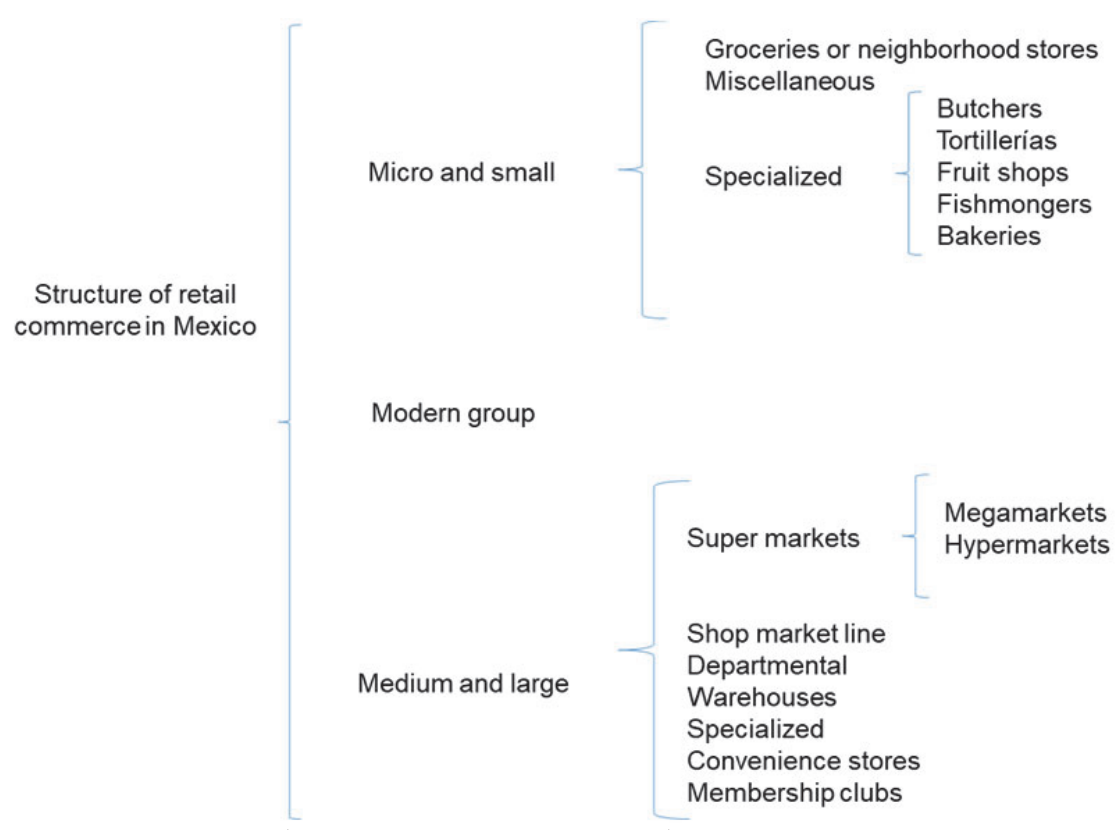

Source: (Bocanegra, 2008, page 124) 
The retail trade continues to be through the years the economic activity very important for a community, a region and for the country in general. It also provides the opportunity for the owners of these organizations to have a direct and unique relationship with their final consumer.

\section{Supermarkets}

"The self-service stores emerged in the early twentieth century, were characterized by not having staff for direct attention to the public. Therefore, the client had direct access to the product, without the attention of its owner or dependent. The prices were previously determined, which at that time was an innovation in sales. As well as at this stage, it was the fact that the products carried the brands of the manufacturers, with the characterization of the product. This led to the start of competition between the brands of different producers. In essence this step in the commercialization of retail products, radically changed the display of articles, customer service, price, distribution, packaging and presentation design" (ANTAD, History of trade ... sf: 21-26; Bocanegra, 2008, pp. 118,119).

For the specific case of Mexico, the first supermarket that opened its doors to the public was a first of December 1958, at the corner of Bolívar and Chimalpopoca a crowd lined up to enter the first self-service store, which mainly sold clothing With discounts, after a short time a great variety of articles was added, it was called "Central de Ropa" but later I adopted a definitive name that immediately caught on among the people: Aurrera "ahead" in the Basque language. It was the beginning of supermarkets in our country (Solorzano, 2008).

The entry into the scene of supermarkets as happened in other countries, meant a profound transformation in retail, as in our country were marketed through public markets, or markets on wheels, neighborhood stores or groceries, convenience stores and specialty stores (Lopez, Segovia, Garcia, \& Beade, 2014, page 2).

The same authors say that at that time began to establish in the country, a few commercial chains whose presence was notorious especially in large cities and particularly in the neighborhoods of middle and upper class, so in those early years you could say that only satisfied the needs of the population that lived in the mentioned areas.

It was until the late eighties and the nineties that the economic, political and social conditions prevailed, so that supermarkets could expand with dynamism and consolidate as we know them today. (Lopez, Segovia, Garcia, \& Beade, 2014, page 2).

Mexico, like many of the Latin American developing countries, was at that time when economic liberation processes were carried out, in our country the changes in the National Law of Foreign Investments, which allowed the entry of both capital and foreign investment, which encouraged the entry of American and European channels, which were gradually established, first through alliances with local commercial chains and then through purchase of these. Along with this change, the process of urbanization and construction of infrastructure and roads that connected small cities to capital cities played an important role, which reduced costs and expanded the possibilities for them to settle in these areas (Lopez, Segovia, Garcia, \& Beade, 2014).

\section{Management by Competencies}

Competency management is a crucial tool for personnel management, more adjusted to the key characteristics of human capital, which make up the company's workforce and those that make it possible for a specific job to be developed efficiently. The activities that must change are: recruitment and selection of personnel should seek people with appropriate skills to the culture, values, and performance characteristics of their different activities (Moreno Dominguez, Pelayo, and Vargas, 2004).

The same authors in their study conclude that competency management can generate major advantages such as: positive impact on the performance of work, improves the work environment, facilitates the decision regarding people with their jobs, favors the development of teams, ability to face changes, greater participation of employees, motivation is improved and contributes to achieve better business results. (Moreno Dominguez, Pelayo, \& Vargas, 2004). 


\section{The Competencies}

Benavides Espíndola (2001), in his book Competitions and Competitiveness Design for Latin American Organizations, points out that the term competences is introduced in the business jargon from Boyatzis with the publication of his book The competent manager, which reached great popularity at the end of the 1980s. The use became generalized quickly in the European countries and spread from its original focus in England (1980), a country that consolidates the model in the private sector in the initial attempt to review and adapt the training and training systems to prepare for the next competition of globalization. Given the results achieved by the experimental sectors, it is introduced as tools for the achievement of public efficiency in the administration of Margaret Tatcher. Later it is projected in France based on the participatory paradigms of the constructivist current of Bertrand Schwartz, and in America it appears with a behavioral approach defined for the United States by David Mc Clelland and Harvard University. And in Canada it approaches the English functionalist model. In addition, some students of psychology interpreted competences as a trait, a term that does not cover the scope of these competencies.

The same author Benavides Espindola (2001) comments that others attribute the origin of the competences to Mc Cleland and that during the 1970s he planned motivational investigations related to the study of shortcomings in low job performance, but in this case the orientation was cut clinical, with this result the sense of the integrated concept is distorted to labor and occupational competences. However, years later it is oriented towards the evaluation of personal qualification and job performance and ventures into an approach and use of new skills in the workplace and especially in the management of human resources.

He concludes that talent is like the motor of behavior and that it is related to motives, desires, tastes and values. This current is positioned especially in the USA. and its approach is behavioral (Benavides, 2001).

For Claude Levy - Leboyer in (Alles, 2007) summarizes the subject of competences in the following way:

- Competencies are a list of behaviors that some people possess more than others, which make them more effective for a given situation.

- These behaviors are observable in the daily reality of work and equally in situations of evaluation. They apply in an integral way their aptitudes, their personality traits and their acquired knowledge.

- The competences represent a feature of union between the individual characteristics and the qualities required to conduct professional missions correctly.

For the Service of Policies and Training Systems (POLFORM) of the International Labor Organization (ILO), labor competency is the social construction of meaningful and useful learning for productive performance in a real work situation that is obtained not only through of instruction, but also and to a large extent through learning from experience in specific work situations (Ducci 1997), and adds the author has defined professional competence as the ability to perform a task or perform a job effectively for possessing the qualifications required for it (Sánchez, Marrero and Marínez, 2005).

\section{The Components of Personal Competences}

According to the strategic model for the management of human resources, it shows us the components of personal competencies can be classified into two components:

1. The knowledge, are the basic and indispensable elements to perform the precise functions to achieve the business objectives.

2. The professional qualities reflect the set of behavior patterns, observable and measurable personal characteristics, necessary to develop daily activities (Fernandez, Lopez, 2006).

Types and Classification of Competencies

Within the study of competencies we find different types of competences such as: For Spencer and Spencer, in (Alles, 2007) there are five main types of competences:

1. Motivation 
2. features

3. Own concept or self concept

4. Knowledge

5. Ability

Skills of knowledge and skill tend to have visible and relatively superficial characteristics. The competences of self-concept, characteristics and motivations are more hidden within the personality (Alles, 2007). (Zayas Agüero, 2010) Developed a generic competency model that explains the successful performance of the managerial activity composed of the following competencies:

1. Management and action by objectives

2. Leadership

3. Human resources management

4. Direct subordinates

5. Focus on other people

6. Specific knowledge

Olga Benavides Espíndola (2001), indicates that studies in organizations are conceived around three types of fundamental competencies which implies discrimination and use in accordance with the objectives proposed by the intervention or organizational co-intervention. The types of competences are:

1. Generic competitions

2. Labor competences

3. Basic skills

Where generic competences are considered as a series of characteristics required by individuals that can be generalized in a company, entity, consortium, sector or State. The purpose of the same is aimed at strengthening the entity, considering that they arise from each company according to their policies and objectives; These variables are fundamental for the determination of competencies based on organizational orientation. (Benavides, 2001).

The same author, Benavides Espíndola (2001), expresses that labor or management competence is the set of visible personal attributes that are contributed to the work or behaviors to achieve an ideal and efficient performance. The labor competencies integrate characteristic elements of the human being:

1. Knowledge

2. Skills and abilities

3. Selfconcept

4. Traits and temperament

5. Reasons and needs

\section{Job Positions and Job Analysis}

A job consists of a group of activities and related duties, these activities must be clear and different from those of other positions to minimize misunderstandings and the possibilities of conflict among employees as well as to enable them to know what is expected of his performance in the posts. (Bohlander \& Scott, 2008)

Post analysis is a process to obtain information about the positions by determining the duties, tasks or activities thereof. The procedure involves investigating systematically by following a series of predetermined and specified steps before conducting the study. The final purpose of the job analysis is to improve the performance and productivity of the organization. (Bohlander \& Scott, 2008)

\section{METHODOLOGY}

The present investigation was carried out through a quantitative and cross-sectional approach with which the profile of customer service positions in supermarkets is known, which is integrated with essential personal skills such as attitude, aptitude and capacity, which They must have the employees who will cover these positions. The sample size was 384 surveys and captured in the statistical software IBM.SPSS.Statistics.v21 in which the descriptive and correlational analysis was done to determine the 
variables that had the greatest influence, for which the mean of the dimension was determined. to be taken as a dependent variable and the items of the dimension as independent variables.

\section{Sample Design}

To determine the size of the sample, the finite population formula was used, given that the number of people that make up the universe is known, since the statistical data provided by the stores' management, the average daily customer is 7010. 5 supermarkets where the study was carried out, and the days of the week with the highest influx in the supermarkets assigned to research, are Friday, Saturday and Sunday so the universe is 21,030 customers and applying the formula (see development) gives us a sample of 384 surveys, which were prorated based on the highest average inflow per supermarket. (Fisher and Navarro, 1992).

$$
\boldsymbol{n}=\frac{\boldsymbol{N} * \boldsymbol{Z}_{\boldsymbol{a}}^{2} * \boldsymbol{p} * \boldsymbol{q}}{\boldsymbol{d}^{2} *(\boldsymbol{N}-\mathbf{1})+Z_{\boldsymbol{a}}^{2} * \boldsymbol{p} * \boldsymbol{q}}
$$

where: $\mathrm{n}=$ Sample size

$\mathrm{N}=$ Universe to sample 21,030

$\mathrm{Z}=$ Reliability, equivalent to $95 \%$, represented by 1.96

$\mathrm{p}=$ Probability that the event is known or occurs $50 \%$

$\mathrm{q}=$ Probability that the event is not known or occurs $50 \%$

$\mathrm{e}=$ Estimation error (in this case $5 \%$ )

$$
384=\frac{21030 * 1.96 * 50 * 50}{7 *(2138-1)+1.96 * 50 * 50}
$$

\section{Data Collection}

The target population was the clients of the selected establishments that are managed by the coordination that was assigned by the company for this investigation. The sample size was 384 surveys, applied in stratified form, according to the data of the clients that visit the establishments daily, information provided by the management based on the sales payment records in the boxes, and the distribution of surveys by establishment was as follows:

TABLE 1

\section{SURVEYS APPLIED BY ESTABLISHMENT}

\begin{tabular}{lcc}
\hline Establishment & Number of daily customers & Surveys applied \\
\hline Quiroga Square & 800 & 44 \\
\hline Paseo Rio & 1350 & 74 \\
\hline New Hermosillo & 2140 & 117 \\
\hline North Gate & 1500 & 82 \\
\hline Plaza del Rey & 1220 & 67 \\
\hline Total & 7010 & 384 \\
\hline
\end{tabular}

Source: Own elaboration, 2016.

\section{Unit of Analysis: Supermarkets}

The customer service units that were chosen by the company's coordination are five self-service supermarkets mentioned above, and led by the coordination of the company Súper del Norte, in which permission was granted to assist the researcher, with In order to carry out the present study. 


\section{ANALYSIS OF RESULTS}

Supermarkets are very dynamic organizations that need innovative strategies in relation to customer service, orientation and satisfaction, it is important the role of the human resources department in relation to their job profiles, these should be focused on essential skills such as they are attitude, aptitude and ability.

In this investigation the clients look for the attitude of the employees in relation to the kindness and cordiality in their attention, likewise the clients recognize that the collaborators have the capacity to offer a fast and efficient service.

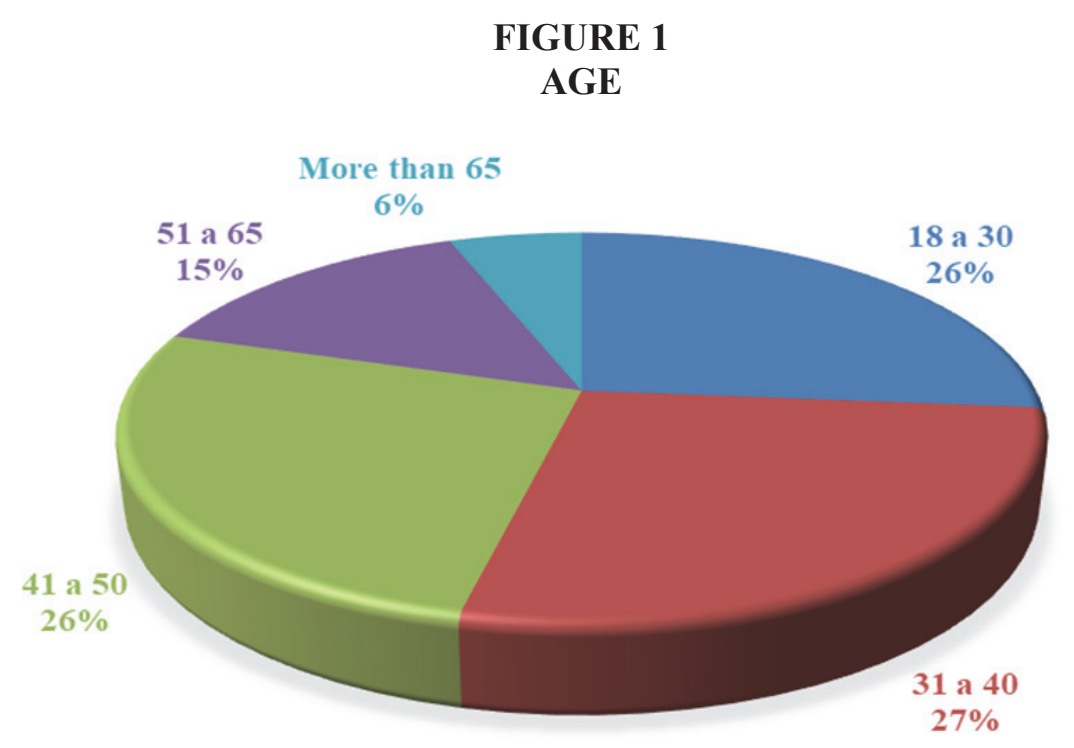

Source: Own Development.

In the age question of the respondents it shows that $26 \%$ oscillates between 18 to 30 years, $27 \%$ oscillates between 31 to 40 years, 26\% oscillates between 41 to 50 years, $15 \%$ oscillates between 51 and 65 years and $6 \%$ have more than 65 years.

FIGURE 2

SEX

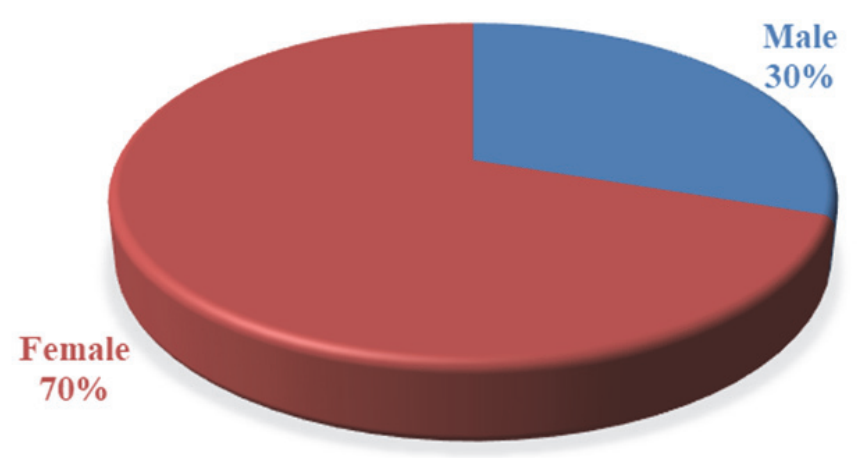

Source: Own Development.

In the question about the respondent's sex, $70 \%$ is female and $30 \%$ is male. 


\section{FIGURE 3 \\ OCCUPATION}

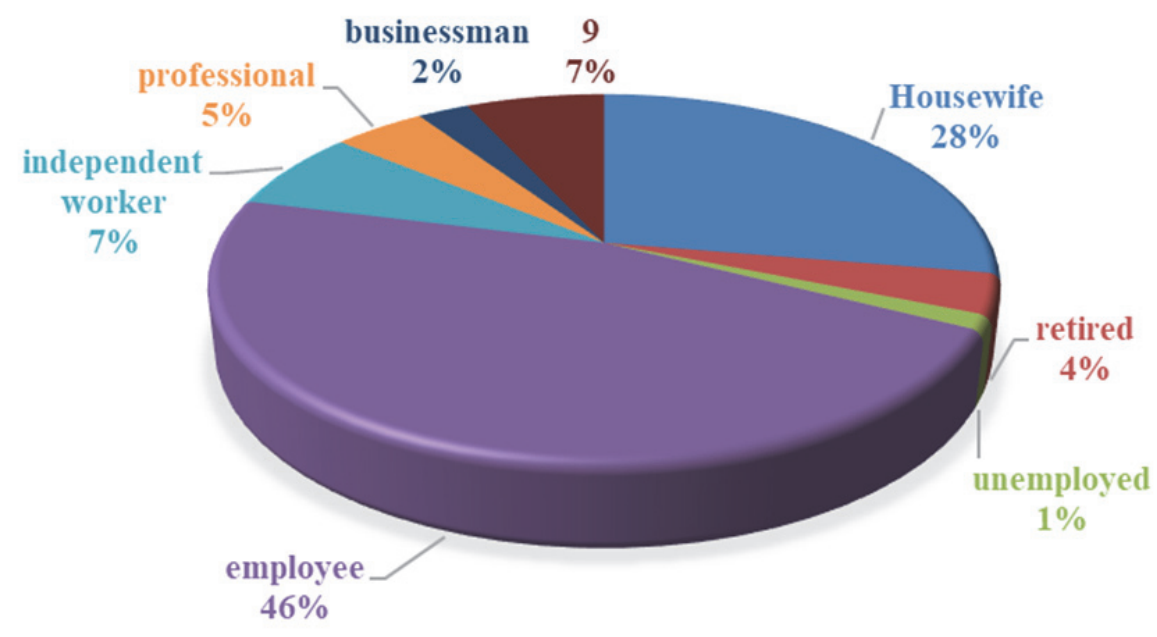

Source: Own Development.

In the question about the occupation of the respondents, $46 \%$ are employed, $28 \%$ are housewives, $7 \%$ work on their own, $5 \%$ are professionals, $2 \%$ are entrepreneurs and $1 \%$ are unemployed.

\section{FIGURE 4 \\ INCOME LEVEL}

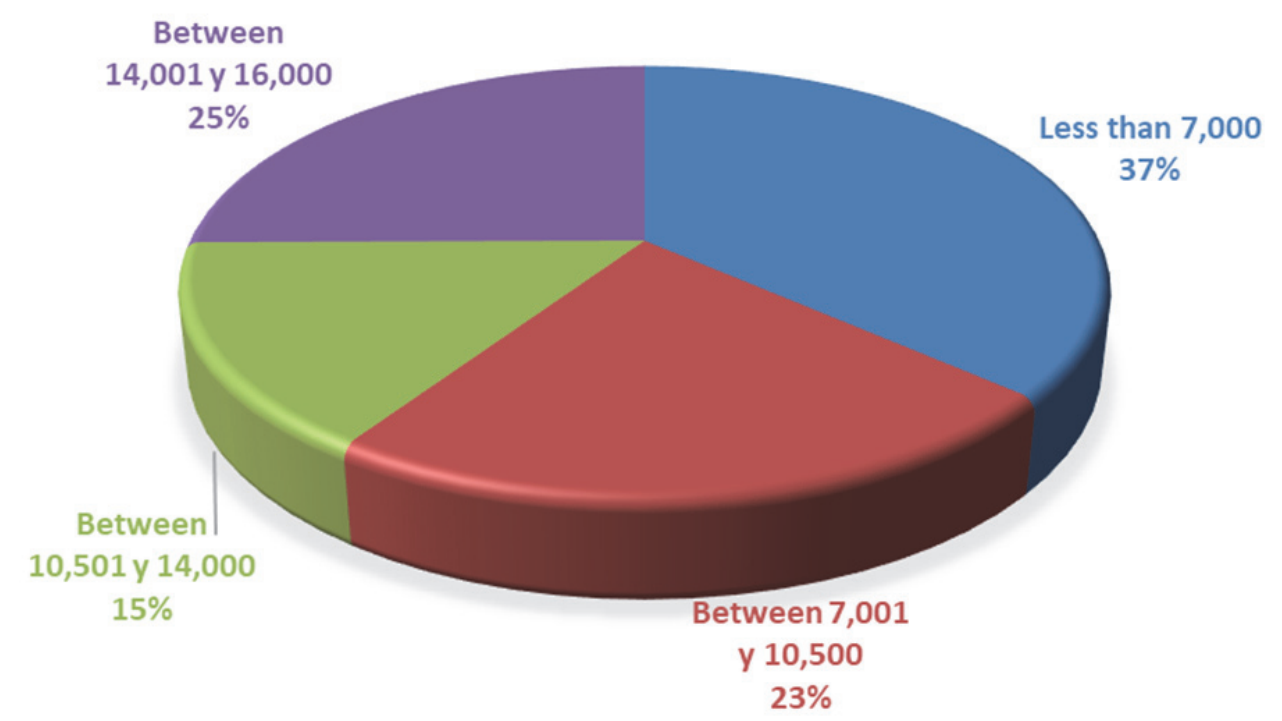

Source: Own Development.

In the question about the income level of the respondents, $23 \%$ have incomes between $\$ 7,001.00$ and $\$ 10,500.00$ pesos, $25 \%$ have incomes between $\$ 14,001.00$ and $\$ 16,000.00$ pesos, $15 \%$ have incomes between $\$ 10,501.00$ and $\$ 14,000.00$ pesos and only the $37 \%$ have incomes below $\$ 7,000.00$ pesos. 
TABLE 2

CORRELATIONS

\begin{tabular}{|c|c|c|c|c|c|c|}
\hline \multirow{4}{*}{ MEDG1 } & & MEDG1 & & MEDG5 & & MEDG3 \\
\hline & $\begin{array}{l}\text { Pearson } \\
\text { correlation }\end{array}$ & one & \multirow[t]{3}{*}{ MEDG5 } & one & \multirow[t]{3}{*}{ MEDG3 } & one \\
\hline & \begin{tabular}{|l|l|}
$\begin{array}{l}\text { Next } \\
\text { (bilateral) }\end{array}$ \\
\end{tabular} & & & & & \\
\hline & $\mathrm{N}$ & 384 & & 384 & & 384 \\
\hline \multirow{3}{*}{$\begin{array}{l}1.7 \text { The } \\
\text { cashier's } \\
\text { attention is } \\
\text { kind }\end{array}$} & $\begin{array}{l}\text { Pearson } \\
\text { correlation }\end{array}$ & $.702^{* *}$ & \multirow{3}{*}{$\begin{array}{l}5.1 \text { The prices in } \\
\text { the supermarket } \\
\text { are competitive in } \\
\text { relation to the } \\
\text { competition }\end{array}$} & $.402^{* *}$ & \multirow{3}{*}{$\begin{array}{l}3.1 \text { The } \\
\text { supermarket is } \\
\text { clean and airy }\end{array}$} & $.489^{* *}$ \\
\hline & \begin{tabular}{|l} 
Next \\
(bilateral)
\end{tabular} & .000 & & .000 & & .000 \\
\hline & $\mathrm{N}$ & 384 & & 384 & & 384 \\
\hline \multirow{3}{*}{$\begin{array}{l}\text { 1.8 The parcel } \\
\text { service is } \\
\text { friendly and } \\
\text { cordial }\end{array}$} & \begin{tabular}{|l} 
Pearson \\
correlation
\end{tabular} & $.667^{* *}$ & \multirow{3}{*}{$\begin{array}{l}5.2 \text { The quality of } \\
\text { attention I receive } \\
\text { as a client } \\
\text { motivates me to } \\
\text { buy at the } \\
\text { supermarket } \\
\text { "Súper del Norte" }\end{array}$} & $.473^{* *}$ & \multirow{3}{*}{$\begin{array}{l}3.2 \text { In the meat } \\
\text { department, } \\
\text { employees are } \\
\text { hygienic when } \\
\text { providing their } \\
\text { services }\end{array}$} & $.500^{* *}$ \\
\hline & \begin{tabular}{|l|} 
Next \\
(bilateral)
\end{tabular} & .000 & & .000 & & .000 \\
\hline & $\mathrm{N}$ & 384 & & 384 & & 384 \\
\hline \multirow{3}{*}{$\begin{array}{l}1.9 \text { In the } \\
\text { department of } \\
\text { Service and } \\
\text { customer } \\
\text { service are } \\
\text { friendly }\end{array}$} & $\begin{array}{l}\text { Pearson } \\
\text { correlation }\end{array}$ & $.726^{* *}$ & \multirow{3}{*}{$\begin{array}{l}5.3 \text { I would like } \\
\text { the home service } \\
\text { to be offered. }\end{array}$} & $.645^{* *}$ & \multirow{3}{*}{\begin{tabular}{|l|}
3.3 In the meat \\
department the \\
employees do not \\
wear the uniform \\
which makes \\
them look less \\
hygienic.
\end{tabular}} & $.306^{* *}$ \\
\hline & \begin{tabular}{|l|} 
Next \\
(bilateral)
\end{tabular} & .000 & & .000 & & .000 \\
\hline & $N$ & 384 & & 384 & & 384 \\
\hline \multirow{3}{*}{$\begin{array}{l}1.10 \text { Security } \\
\text { guards give me } \\
\text { confidence and } \\
\text { are kind }\end{array}$} & \begin{tabular}{|l|l|} 
Pearson \\
correlation
\end{tabular} & $.707^{* *}$ & \multirow{3}{*}{$\begin{array}{l}\text { 5.4 I would like } \\
\text { to purchase food } \\
\text { prepared } \\
\text { internally }\end{array}$} & $.626^{* *}$ & \multirow{3}{*}{\begin{tabular}{|l|}
3.4 In the meat \\
department has \\
the equipment \\
(grinding \\
machine, saw \\
and knives) \\
necessary to \\
provide the \\
service I require
\end{tabular}} & $.637^{* *}$ \\
\hline & $\begin{array}{l}\text { Next } \\
\text { (bilateral) }\end{array}$ & .000 & & .000 & & .000 \\
\hline & $\mathrm{N}$ & 384 & & 384 & & 384 \\
\hline \multicolumn{3}{|c|}{$\begin{array}{l}\text { ** The correlation is significant at the } 0.01 \\
\text { level (bilateral). }\end{array}$} & \multirow{3}{*}{$\begin{array}{l}\text { 5.5 I would like } \\
\text { to be granted a } \\
\text { "Super del Norte" } \\
\text { purchase loyalty } \\
\text { card }\end{array}$} & $.524^{* *}$ & \multirow{3}{*}{$\begin{array}{l}3.5 \text { The } \\
\text { department of } \\
\text { Salchichoneria is } \\
\text { clean }\end{array}$} & $.547^{* *}$ \\
\hline & & & & .000 & & .000 \\
\hline & & & & 384 & & 384 \\
\hline & & & \multirow{3}{*}{$\begin{array}{l}5.6 \text { I recommend } \\
\text { to my relatives } \\
\text { and } \\
\text { acquaintances at } \\
\text { the supermarket } \\
\text { "Super del Norte" }\end{array}$} & $.438^{* *}$ & \multirow{3}{*}{$\begin{array}{l}\text { 3.6 The } \\
\text { Salchichoneria } \\
\text { department lacks } \\
\text { improvement in } \\
\text { hygiene and } \\
\text { cleanliness }\end{array}$} & $.232^{* *}$ \\
\hline & & & & .000 & & .000 \\
\hline & & & & 384 & & 384 \\
\hline
\end{tabular}




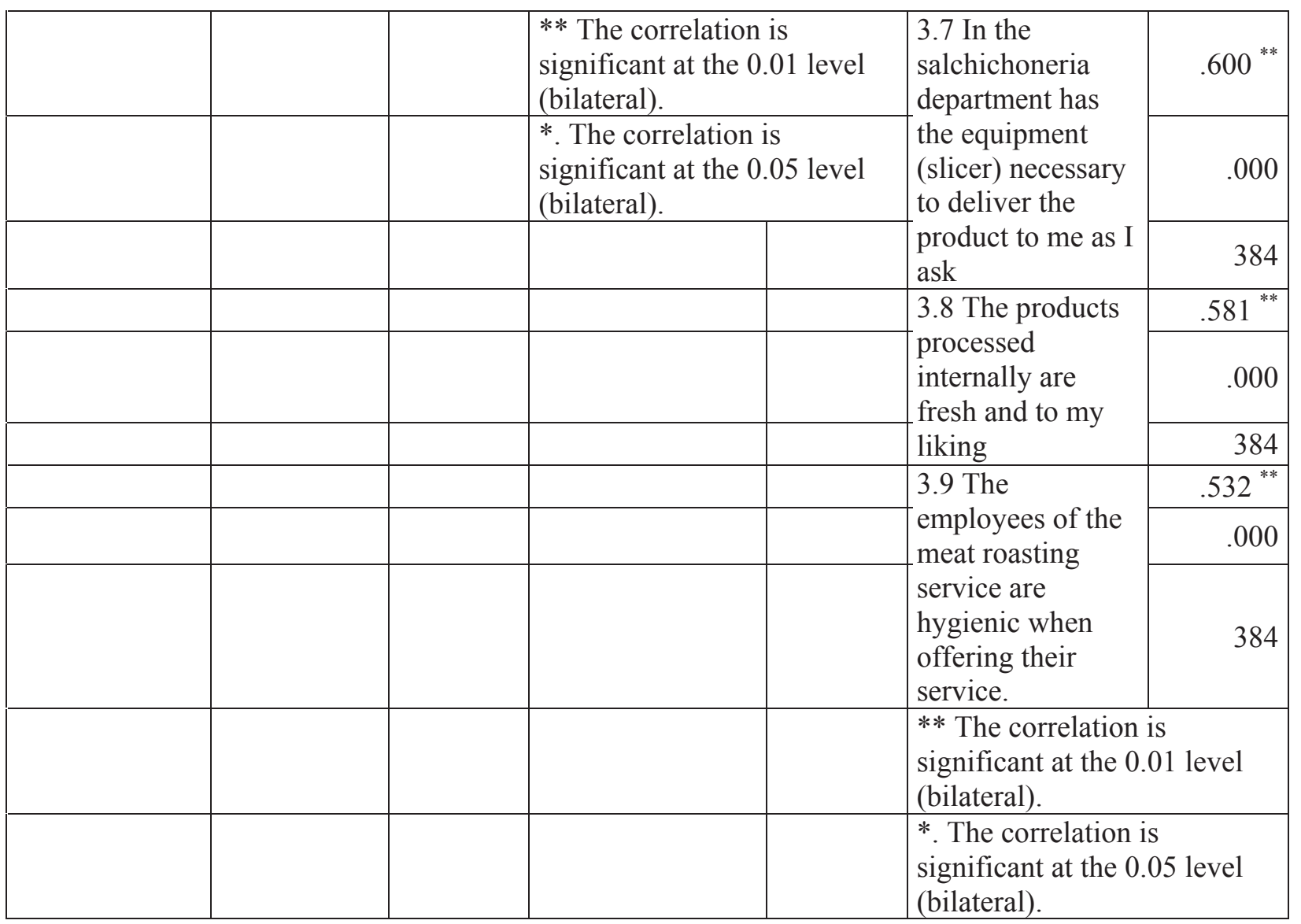

The results of the correlational analysis of the dimensions give us significant results such as, in the assessment of the attitude of the employees to the client, it tells us that the variable, in the department of Service and customer service are kind, shows that $\mathbf{r}=\mathbf{7 2 6} * *$, Sig. (Bilateral) .000 , in the dimension, assessment of Hygiene and work equipment of the supermarket, the variable, in the meat department has the equipment (grinding machine, saw and knives) necessary for provide the service I require, throws that $\mathbf{r}=\mathbf{. 6 3 7}{ }^{* *}$, Sig. (bilateral) $\mathbf{. 0 0 0}$, in the dimension, valuation of prices and additional services of the supermarket, variable, I would like to offer the service at home, throws that $\mathbf{r}=\mathbf{. 6 4 5}{ }^{* *}$, Sig. (bilateral) $\mathbf{0 0 0}$; The study shows that employees of customer service departments must respond at all times in a cordial and friendly manner and have knowledge of the teams with which they work to provide a quality service, and the concern shown by customers about a home service shows that customers at all times demand more staff for which they are served

\section{CONCLUSION}

It is important to mention that the objectives that were intended to be achieved were achieved, with which the profiles of the customer service positions of the supermarkets were determined in order to issue the pertinent recommendations.

Today, companies are obliged to standardize their recruitment and personal selection processes based on job profiles, and supermarkets are not the exception as they must know the ideal profiles for the positions that serve customers, as well have a recruitment process, hiring more agile and with the certainty in search of the attention, orientation, satisfaction and preference of the clients as part of the own culture of these organizations. 
It is recommended to continue looking for links with the productive sector to continue with these investigations in relation to the needs that are had in relation to the administration of their human resources.

\section{REFERENCES}

Alles, M. (2007). Strategic Management of Human Resources Management by competences. Argentina: GRANICA.

Benavides, E.O. (2001). Competencies and Competitiveness Design for Latin American organizations. Bogota: McGraw Hill.

Bocanegra, G.C. (2008). Trade in Mexico and its encounter with globalization. Hermosillo: University of Sonora.

Bohlander, G., \& Scott, S. (2008). Human resources management. Mexico, DF: CENGAGE, Learning.

Lopez, P., Segovia, A., Garcia, C., \& Beade, A. (2014, December 12). Retrieved December 8, 2014, from http://www.profeco.gob.mx/encuesta/brujula/bruj_2013/bol244_tiendas_autoservicio.asp:

Moreno Dominguez, M.J., Pelayo, D.Y., \& Vargas, S.A. (2004). Management by Competencies as a Tool for the Strategic Management of Human Resources in the knowledge society. Company, 56-72.

Solorzano, E. (2008). Wal-Mart Mexico a story of courage and commitment. Mexico: Clio.

Zayas Agüero, PM. (2010). The One A Theoretical - Methodological Competencies. Contributions to the Economy, 1-18. 